\title{
Gençlik ve Spor Merkezinde Düzenlenen Kurslara Katılan Gençlerin Fair-Play Davranışlarının Bazı Değişkenler Açısından İncelenmesi
}

\author{
Nedim Burak Yıldırım ${ }^{1 *}$, Kemal Göral ${ }^{2}$ \\ ${ }^{1}$ İzmir Katip Çelebi Üniversitesi, İzmir, Türkiye \\ ${ }^{2}$ Muğla Sitkı Koçman Üniversitesi, Spor Bilimleri Fakültesi, Muğla, Türkiye \\ email: nedimburakyildirim@hotmail.com, kgoral1980@yahoo.com \\ Orcid: 0000-0002-6958-1048 \\ Orcid: 0000-0001-8030-2276 \\ *Sorumlu Yazar / Corresponding Author: Sorumlu Yazar: Nedim Burak Y1ldırım \\ Gönderim Tarihi / Received: 24.05.2019 \\ Kabul Tarihi / Accepted: 03.12.2019 \\ DOI: $10.34087 /$ cbusbed.569863
}

\begin{abstract}
Amaç: $\mathrm{Bu}$ araştırmanın amacı, gençlik ve spor merkezlerinde çeşitli branşlarda düzenlenen kurslara katılan bireylerin fair-play davranışlarının çeşitli değişkenler açısından incelenmesidir.

Materyal ve Metod: Araştırmada genel tarama modeli kullanılmış ve çalışmaya Samsun ilinde gençlik ve spor merkezlerinde açılan kurslara katılan 137 kadın ve 313 erkek olmak üzere toplam 450 kişi katılmıştır. Katılımcıların yaş ortalaması 19.38 1.59 olarak belirlenmiştir. Araştırmaya katılan bireylerin fair-play davranışlarını tespit etmek için Mirzeoğlu (2015) tarafından Türkçeye uyarlanan Beden Eğitimi Fair-Play ölçeği kullanılmıştır. Araştırma kapsamında toplanan veriler SPSS 18.00 paket programında kayıt altına alınmıştır. Ölçeğin katılımcı gruba uygunluğunu test etmek için AMOS programında doğrulayıcı faktör analizi kullanılmıştır.

Bulgular: Araştırmada elde edilen bulgulara göre, kadınların haksız kazanma ve hile boyutlarındaki değerleri erkeklerden daha yüksek çıkarken, fair-play davranışlarının branşlara göre farklılaşmadığ 1 tespit edilmiştir. Katılımcıların öğrenim durumlarının, arkadaşa saygı boyutu dışında, fair-play davranışını değiştirmediği belirlenmiștir.

Sonuç: Sonuç olarak, Gençlik ve spor merkezlerinde açılan kurslara katılan bireylerin fair-play davranışlarının toplam değerinin cinsiyetlere göre değişmediği, bireylerin anne ve baba eğitim durumlarının fair-play davranışında kısmen farklılıklar oluşturduğu, aylık gelirin ise fair-play davranışlarında farklılık oluşturmadığı görülmüştür.

Anahtar Kelimeler: Fair Play, Gençlik Ve Spor, Beden Eğitimi.
\end{abstract}

\begin{abstract}
Aim: The aim of this study is to investigate the fair play behaviors of individuals who attend courses in various branches in youth and sports centers in terms of various variables.

Material and Methods: General screening model was used in the research. The population of the study was comprised of individuals participating in the courses opened in youth and sports centers in Samsun province while the sample included 137 women and 313 male participants. The mean age of the participants was $19.38 \pm 1.59$. In order to determine the fair-play behaviors of the participants, Physical Education Fair-Play scale which is adapted to Turkish by Mirzeoğlu (2015) was used. The data collected within the scope of the study were recorded in SPSS 18.00 package program. Confirmatory factor analysis was used in the AMOS program to test the suitability of the scale to the participant group.

Results: It was found that Fair-play behaviors did not differ according to the branches. It was determined that the educational level of the participants did not change the behavior of fair-play except for respect to friends. Conclusion: Consequently, it was determined that the total value of fair play behaviors of the individuals participating in the courses opened in youth and sports centers did not change according to the genders.
\end{abstract}

Keywords: Fair Play, Youth And Sport, Physical Education.

\section{Giris}

Fair play kavramı, müsabaka ve yarıșmalarda sergilenen iyi ve kötü davranışlar için standart bir kavram olarak gelişmiştir. "Fair" kavramı, on ikinci yüzyılda tarafsızlık ve adalet olarak tanımlanırken, bu kavramın gelişiminin başlangıcı için, on beşinci yüzyılın ikinci yarısında İngiliz şiirlerinde yer alan "Fayre Game" ve turnuvalarda oyun kuralları olarak uygulanan centilmenlik dışı davranış olarak tanımlanan "faoul play" ifadelerine götürülebilir. İlk zamanlarda ticaretle ilgili bir kavram olan " fair-play”in, daha sonra genel 
olarak firsat eşitliğini korumak, şövalyelik idealini göstermek anlaminda Shekespeare'in "The Life and Death of King John" adlı eserinde geçtiği ve on sekizinci yüzyılda da spor diline giriş yaptığ görülmektedir [2, 4, 14].

Gençlerin ve çocukların spor ahlakının kurallarını bilmelerine rağmen, onu uygulamaya koymaktaki eğilimleri çok azdır. Kanada'da yapılan bir çalışma, 1117 yaş arası 1056 genç sporcunun \%57'sinin bir rakibinin hatasında puan kazanmaktan, özellikle de bu puanlar onlar için ya da takımları için galibiyeti getirecekse, yararlanacaklarını doğrulamaktadır. \%71'i eğer yarışı kaybetmelerine neden olacak riskteki hatayı işlemişse, görevliyi açıkça eleştireceklerini belirtmişlerdir [6]. Spor ortamında giderek s1k görülmeye başlayan erdemsiz davranışlar, okullardaki beden eğitimi ve spor ortamını da etkilemiş, 1970lerden sonra beden eğitimi dersinin önemli faktörlerinden biri olan sosyalleştirme eğiliminin fair-play'e yönelik davranışları garanti altına alamadığı görülmüştür [15].

Gençlik ve spor merkezleri, bireylerin çeşitli branşlarda açılan kurslara katılarak sosyal ve sportif bir çevreye katılmalarını sağlamaktadır. Gençlik ve spor merkezleri bu yönüyle toplumsal gelişime katkı sağlamaktadır. Dolayısıyla, sporda ahlaki davranışların yaygınlaşmasında, toplumun farklı kesimlerden bireyleri sportif ve sosyal bir ortamda toplayan gençlik ve spor merkezlerinin rolü büyüktür. Bu kurslara katılan bireylerin fair-play davranışlarının incelenmesi sporda ahlaki davranışların toplum içerisinde yaygınlaştırılmasına katkı sağlayacaktır. Bu araştırmanın amacı gençlik ve spor merkezlerinde çeşitli branşlarda düzenlenen kurslara katılan bireylerin fairplay davranışlarını çeşitli değişkenler açısından incelemektir.

\section{Materyal ve Metot}

Araştırmada genel tarama modeli kullanılmıştır. Araştırma Muğla Sitkı Koçman Üniversitesi İnsan Araştırmaları Etik Kurulu tarafından 19.04.2018 tarihli 56 sayılı kararla uygun bulunmuştur (protokol no: 180010)

Araştırmaya, Samsun ilinde gençlik ve spor merkezlerinde açılan kurslara katılan 137 kadın ve 313 erkek olmak üzere, yaş ortalaması $19.38 \pm 1.59$ olan toplam 450 kişi katılmıştır. Araştırmaya katılan bireyler, yüzme $(n=100)$, tenis $(n=50)$, futbol $(n=100)$, güreş $(n=100)$, voleybol $(n=50)$ ve basketbol $(n=50)$ branşlarında yer almaktadır.

Kişisel Bilgi Formu: Araştırmada bireylerin demografik değişkenlerine ilișkin bilgileri tespit etmek için araştırmacı tarafından düzenlenen kişisel bilgi formu kullanılmıştır.

Beden Eğitimi Fair-Play Ölçeği: Araştırmaya katılan bireylerin fair-play davranışlarını tespit etmek için Mirzeoğlu (2015) tarafindan Türkçeye uyarlanan Beden
Eğitimi Fair-Play ölçeği kullanılmıştır. Ölçek 15 maddeden oluşmaktadır. Ölçeğin takım arkadaşlarına sayg1, geleneklere sayg1, haksız kazanma ve hile olmak üzere dört alt boyutu bulunmaktadır. Ölçek maddeleri 15 arasında puanlanmaktadır. Orijinal ölçeğe ilişkin iç tutarlılık katsayısı. 65 olarak bulunurken bu çalışmada alfa katsayısı. 67'dir. .60 üzerinden alfa katsayıları kabul edilebilir düzeydedir (Nunnally ve Bernstein, 1994). Bu araştırmada, ölçeğin katılımcı gruba uygun olup olmadığını test etmek için doğrulayıcı faktör analizi yapılmış, ölçeğin uyum indeksleri iyi düzeyde çıkmıştır $\quad(\mathrm{x} 2=179.31, \mathrm{df}=82, \mathrm{x} 2 / \mathrm{df}=2.18, \mathrm{GFI}=.95$, AGFI $=.92, \quad$ TLI $=.96, \quad$ CFI $=.97, \quad$ SRMR $=0.04$, RMSEA=0.05) (Hu ve Bentler, 1998).

Verilerin analizi: Araştırma kapsamında toplanan veriler SPSS 18.00 paket programında kayıt altına alınmıştır. Ölçeğin katılımcı gruba uygunluğunu test etmek için AMOS programında doğrulayıcı faktör analizi uygulanmıştır. Katılımcıların kişisel bilgilerine ilişkin analizler için yüzde ve frekans analizleri, iki değişken arasındaki analizler için bağımsız t test, ikiden fazla değişken arasındaki farklılıkların belirlenmesinde oneway ANOVA, farklılığın hangi grup/gruplardan kaynaklandığını tespit etmek için ise Tukey HSD analizleri yapılmıştır. Değişkenler arasındaki ilişkiyi incelemek için ise Pearson Korelasyon testi kullanılmıştır.

\section{Bulgular}

Araştırmada elde edilen bulgular, bu bölümde tablolar ve grafikler şeklinde sunulmuştur.

Tablo 1. Katılımciların demografik bilgileri

\begin{tabular}{|c|c|c|c|}
\hline \multicolumn{2}{|l|}{ Değişkenler } & $\mathbf{n}$ & $\%$ \\
\hline \multirow[b]{2}{*}{ Cinsiyet } & Kadın & 137 & 30.4 \\
\hline & Erkek & 313 & 69.6 \\
\hline \multirow{6}{*}{ Branş } & Yüzme & 100 & 22.2 \\
\hline & Tenis & 50 & 11.1 \\
\hline & Futbol & 100 & 22.2 \\
\hline & Güreş & 100 & 22.2 \\
\hline & Voleybol & 50 & 11.1 \\
\hline & Basketbol & 50 & 11.1 \\
\hline \multirow{2}{*}{$\begin{array}{l}\text { Öğrenim } \\
\text { Durumu }\end{array}$} & Lise & 399 & 88.7 \\
\hline & Üniversite & 51 & 11.3 \\
\hline \multirow{5}{*}{$\begin{array}{l}\text { Baba öğrenim } \\
\text { durumu }\end{array}$} & İlkokul & 75 & 16.7 \\
\hline & Ortaokul & 165 & 36.7 \\
\hline & Lise & 133 & 29.6 \\
\hline & Üniversite & 67 & 14.9 \\
\hline & Yüksek lisans & 10 & 2.2 \\
\hline \multirow{5}{*}{$\begin{array}{l}\text { Anne öğrenim } \\
\text { durumu }\end{array}$} & İlkokul & 151 & 33.6 \\
\hline & Ortaokul & 175 & 38.9 \\
\hline & Lise & 80 & 17.8 \\
\hline & Üniversite & 39 & 8.7 \\
\hline & Yüksek lisans & 5 & 1.1 \\
\hline \multirow{4}{*}{ Aylık Gelir } & $0-1500$ & 84 & 18.7 \\
\hline & $1500-3000$ & 215 & 47.8 \\
\hline & $3000-5000$ & 103 & 22.9 \\
\hline & 5000 ve üzeri & 48 & 10.7 \\
\hline
\end{tabular}


Araştırmaya katılan bireylerin \%30.4’ü kadın (n=137), \%69.6's1 erkektir (n=313). Katılımciların \%22.2'si yüzme $(n=100), \% 11.1$ 'i tenis $(n=50), \% 22.2$ 'si futbol $(\mathrm{n}=50), \quad \% 11.1^{\prime} \mathrm{i} \quad$ voleybol $\quad(\mathrm{n}=50) \quad$ branşlarından bireylerdir.

$(n=100), \% 22.2$ 'si güreş $(n=100), \% 11.1$ 'i basketbol

Tablo 2. Fair-Play davranışlarının cinsiyet açısından farklılıkları

\begin{tabular}{|c|c|c|c|c|c|c|}
\hline & Cinsiyet & $\mathrm{n}$ & Art.Ort. & Std. Sapma & $\mathrm{t}$ & $\mathrm{p}$ \\
\hline \multirow{2}{*}{ Arkadaşa Saygı } & Kadın & 137 & 6.78 & 2.97 & \multirow[t]{2}{*}{-1.983} & \multirow[t]{2}{*}{.05} \\
\hline & Erkek & 313 & 7.36 & 2.86 & & \\
\hline \multirow{2}{*}{ Geleneklere Sayg1 } & Kadın & 137 & 8.29 & 4.51 & \multirow[t]{2}{*}{-1.931} & \multirow[t]{2}{*}{.05} \\
\hline & Erkek & 313 & 9.17 & 4.46 & & \\
\hline \multirow{2}{*}{ Haksız Kazanma } & Kadın & 137 & 17.40 & 3.48 & \multirow[t]{2}{*}{2.041} & \multirow[t]{2}{*}{$.04 *$} \\
\hline & Erkek & 313 & 16.58 & 4.10 & & \\
\hline \multirow{2}{*}{ Hile } & Kadın & 137 & 14.56 & 1.66 & \multirow[t]{2}{*}{3.630} & \multirow[t]{2}{*}{$.00 *$} \\
\hline & Erkek & 313 & 13.57 & 2.99 & & \\
\hline \multirow{2}{*}{ Fair Play } & Kadın & 137 & 11.76 & 1.66 & \multirow[t]{2}{*}{.468} & \multirow[t]{2}{*}{.64} \\
\hline & Erkek & 313 & 11.67 & 2.99 & & \\
\hline
\end{tabular}

Tablo 2'de fair play davranışlarının cinsiyetler arasındaki analizleri verilmiştir. Buna göre, arkadaşa sayg1 ve geleneklere sayg1 alt boyutlarında cinsiyetler arasında istatiksel olarak anlamlı düzeyde farklılık tespit edilemezken, haksız kazanma ve hile alt boyutlarında cinsiyetler arasında anlamlı farklılık tespit edilmiştir

Tablo 3. Fair-Play davranışlarının branşlara göre değişimi

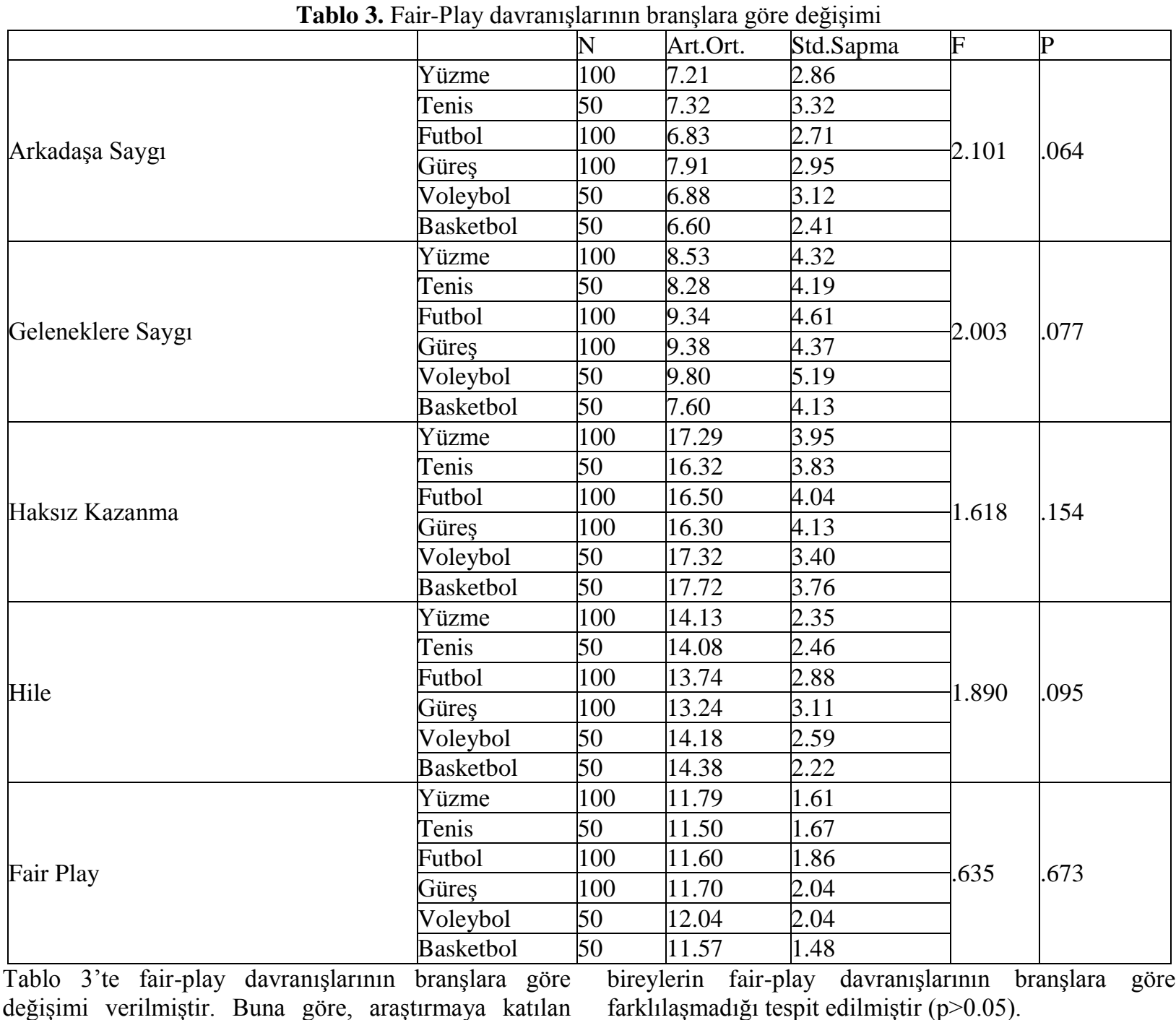

Tablo 3'te fair-play davranışlarının branşlara göre bireylerin fair-play davranışlarının branşlara göre değişimi verilmiştir. Buna göre, araştırmaya katılan $(\mathrm{p}<0.05)$. Kadınların haksız kazanma ve hile çıkmıştır. Toplam fair-play puanlarında ise herhangi bir anlamlı farklılığa rastlanmamıştır $(\mathrm{p}>0.05)$. boyutlarındaki değerleri erkeklerden daha yüksek 
Tablo 4. Fair-Play davranışlarının eğitim durumuna göre değişimi

\begin{tabular}{|c|c|c|c|c|c|c|}
\hline & Öğrenim Durumu & $\mathrm{N}$ & Art.Ort. & Std.Sapma & $\mathrm{T}$ & $\mathrm{P}$ \\
\hline \multirow[b]{2}{*}{ Arkadaşa Saygı } & Lise & 399 & 7.07 & 2.77 & \multirow[t]{2}{*}{-2.382} & \multirow[t]{2}{*}{$.018 *$} \\
\hline & Üniversite & 51 & 8.09 & 3.68 & & \\
\hline \multirow[b]{2}{*}{ Geleneklere Sayg1 } & Lise & 399 & 8.91 & 4.50 & \multirow[t]{2}{*}{.078} & \multirow[t]{2}{*}{.938} \\
\hline & Üniversite & 51 & 8.86 & 4.43 & & \\
\hline \multirow[b]{2}{*}{ Haksız Kazanma } & Lise & 399 & 16.85 & 3.83 & \multirow[t]{2}{*}{.216} & \multirow[t]{2}{*}{.829} \\
\hline & Üniversite & 51 & 16.72 & 4.71 & & \\
\hline \multirow[b]{2}{*}{ Hile } & Lise & 399 & 13.93 & 2.51 & \multirow[t]{2}{*}{1.464} & \multirow[t]{2}{*}{.144} \\
\hline & Üniversite & 51 & 13.35 & 3.82 & & \\
\hline \multirow[b]{2}{*}{ Fair Play } & Lise & 399 & 11.69 & 1.77 & \multirow[t]{2}{*}{.-240} & \multirow[t]{2}{*}{.810} \\
\hline & Üniversite & 51 & 11.75 & 2.12 & & \\
\hline $\begin{array}{l}* \mathrm{P}<0.05 \\
\text { Tablo 4'te fair } \\
\text { durumuna göre } \\
\text { Katılımciların öğren }\end{array}$ & $\begin{array}{l}\text { davranışlarının ö } \\
\text { leğişimi gösteri } \\
\text { urumlarının, arkadas }\end{array}$ & enim & \multicolumn{4}{|c|}{$\begin{array}{l}\text { saygı boyutu dişında, fair-play davranışını } \\
\text { değiştirmediği belirlenmiştir. Arkadaşa saygı alt } \\
\text { boyutunda lise mezunlarının anlamlı düzeyde daha } \\
\text { yüksek puana sahip olduğu görülmüştür }(\mathrm{p}<0.05) \text {. }\end{array}$} \\
\hline
\end{tabular}

Tablo 5. Fair-Play davranışlarının katılımcının baba eğitim durumuna göre değişimi

\begin{tabular}{|c|c|c|c|c|c|c|c|}
\hline & Değişkenler & $\mathrm{N}$ & Art.Ort. & Std.Sapma & $\mathrm{F}$ & Post Hoc & $\mathrm{P}$ \\
\hline \multirow{5}{*}{ Arkadaşa Saygı } & 1-İlkokul & 151 & 3.17 & .42 & \multirow{5}{*}{4.752} & \multirow{5}{*}{$5>1,2,3$} & \multirow{5}{*}{$.001 *$} \\
\hline & 2-Ortaokul & 175 & 3.11 & .52 & & & \\
\hline & 3-Lise & 80 & 3.00 & .49 & & & \\
\hline & 4-Üniversite & 39 & 3.13 & .48 & & & \\
\hline & 5-Yüksek Lisans & 5 & 3.21 & .25 & & & \\
\hline \multirow{5}{*}{ Geleneklere Sayg1 } & 1-İlkokul & 151 & 3.17 & .42 & \multirow{5}{*}{.507} & & \multirow{5}{*}{.730} \\
\hline & 2-Ortaokul & 175 & 3.11 & .52 & & & \\
\hline & 3-Lise & 80 & 3.00 & .49 & & - & \\
\hline & 4-Üniversite & 39 & 3.13 & .48 & & & \\
\hline & 5-Yüksek Lisans & 5 & 3.21 & .25 & & & \\
\hline \multirow{5}{*}{ Haksız Kazanma } & 1-İlkokul & 151 & 3.17 & .42 & \multirow{5}{*}{1.141} & & \multirow{5}{*}{.337} \\
\hline & 2-Ortaokul & 175 & 3.11 & .52 & & & \\
\hline & 3-Lise & 80 & 3.00 & .49 & & - & \\
\hline & 4-Üniversite & 39 & 3.13 & .48 & & & \\
\hline & 5-Yüksek Lisans & 5 & 3.21 & .25 & & & \\
\hline \multirow{5}{*}{ Hile } & 1-İlkokul & 151 & 3.17 & .42 & \multirow{5}{*}{2.245} & & \multirow{5}{*}{.063} \\
\hline & 2-Ortaokul & 175 & 3.11 & .52 & & & \\
\hline & 3-Lise & 80 & 3.00 & .49 & & - & \\
\hline & 4-Üniversite & 39 & 3.13 & .48 & & & \\
\hline & 5-Yüksek Lisans & 5 & 3.21 & .25 & & & \\
\hline \multirow{5}{*}{ Fair Play } & 1-İlkokul & 151 & 11.84 & 1.35 & \multirow{5}{*}{.438} & & \multirow{5}{*}{.781} \\
\hline & 2-Ortaokul & 175 & 11.66 & 1.84 & & & \\
\hline & 3-Lise & 80 & 11.62 & 1.90 & & - & \\
\hline & 4-Üniversite & 39 & 11.70 & 2.10 & & & \\
\hline & 5-Yüksek Lisans & 5 & 12.27 & 1.13 & & & \\
\hline
\end{tabular}

\section{* $\mathrm{P}<0.05$}

Tablo 5'te fair-play davranışlarının katılımcının baba eğitim durumuna göre değişimi verilmiştir. Arkadaşa saygı boyutu dişındaki alt boyutlar ıle toplam fair play puanlarında anlamlı farklılık bulunamamıştır ( $\mathrm{p}>0.05)$. Arkadaşa saygı alt boyutunda babası yüksek lisans mezunu olan bireylerin puanları 1lkokul, ortaokul, lise mezunu olanlardan anlamlı düzeyde daha yüksektir $(\mathrm{p}<0.05)$

Tablo 6'da Fair Play davranışlarının katılımcının anne eğitim durumuna göre değişimi verilmiştir. arkadaşa sayg1 ve hile boyutlarında anlamlı farklılık tespit edilirken $(\mathrm{p}<0.05)$, geleneklere sayg1 ve haksız kazanma boyutlarında herhangi bir anlamlı farklılık bulunamamıștır ( $\mathrm{p}>0.05)$. Arkadaşa saygı alt boyutunda annesi yüksek lisans yapan bireylerin puanı ilkokul ve ortaokuldan mezun olanlardan anlamlı düzeyde daha yüksek bulunurken, hile alt boyutunda annesi yüksek lisans mezunu olan bireylerin puanları ilkokuldan, lise mezunu olanların puanları ilkokul mezunlarından daha düşüktür.

Tablo 7'de katılımcıların aylık gelirlerine göre fair play davranışlarının değişimi verilmiştir. Fair play davranışı alt boyutlarında herhangi bir anlamlı farklılığa rastlanmamıştır $(\mathrm{p}>0.05)$. 
Tablo 6. Fair-Play davranışlarının katılımcının anne eğitim durumuna göre değişimi

\begin{tabular}{|c|c|c|c|c|c|c|c|}
\hline & Değişkenler & $\mathrm{N}$ & Art.Ort. & Std.Sapma & $\mathrm{F}$ & Post Hoc & $\mathrm{P}$ \\
\hline \multirow{5}{*}{ Arkadaşa Saygı } & 1-İlkokul & 151 & 6.87 & 2.77 & \multirow{5}{*}{2.898} & \multirow{5}{*}{$5>1,2$} & \multirow{5}{*}{$.030 *$} \\
\hline & 2-Ortaokul & 175 & 7.17 & 2.74 & & & \\
\hline & 3-Lise & 80 & 7.37 & 3.28 & & & \\
\hline & 4-Üniversite & 39 & 7.61 & 2.76 & & & \\
\hline & 5-Yüksek Lisans & 5 & 10.80 & 5.01 & & & \\
\hline \multirow{5}{*}{ Geleneklere Sayg1 } & 1-İlkokul & 151 & 9.12 & 4.59 & \multirow{5}{*}{.230} & & \multirow{5}{*}{.921} \\
\hline & 2-Ortaokul & 175 & 8.90 & 4.48 & & & \\
\hline & 3-Lise & 80 & 8.62 & 4.61 & & & \\
\hline & 4-Üniversite & 39 & 8.58 & 3.99 & & & \\
\hline & 5-Yüksek Lisans & 5 & 9.40 & 5.07 & & & \\
\hline \multirow{5}{*}{ Haksız Kazanma } & 1-İlkokul & 151 & 17.31 & 3.49 & \multirow{5}{*}{1.585} & & \multirow{5}{*}{.177} \\
\hline & 2-Ortaokul & 175 & 16.86 & 4.03 & & & \\
\hline & 3-Lise & 80 & 15.95 & 4.55 & & & \\
\hline & 4-Üniversite & 39 & 16.71 & 3.59 & & & \\
\hline & 5-Yüksek Lisans & 5 & 16.60 & 4.56 & & & \\
\hline \multirow{5}{*}{ Hile } & 1-İlkokul & 151 & 14.32 & 1.96 & \multirow{5}{*}{3.593} & \multirow{5}{*}{$1>3,5$} & \multirow{5}{*}{$.007 *$} \\
\hline & 2-Ortaokul & 175 & 13.82 & 2.62 & & & \\
\hline & 3-Lise & 80 & 13.17 & 3.82 & & & \\
\hline & 4-Üniversite & 39 & 14.07 & 2.19 & & & \\
\hline & 5-Yüksek Lisans & 5 & 11.40 & 3.57 & & & \\
\hline \multirow{5}{*}{ Fair Play } & 1-İlkokul & 151 & 11.90 & 1.58 & \multirow{5}{*}{.438} & \multirow{5}{*}{-} & \multirow{5}{*}{.781} \\
\hline & 2-Ortaokul & 175 & 11.69 & 1.97 & & & \\
\hline & 3-Lise & 80 & 11.28 & 1.84 & & & \\
\hline & 4-Üniversite & 39 & 11.75 & 1.82 & & & \\
\hline & 5-Yüksek Lisans & 5 & 12.05 & .97 & & & \\
\hline
\end{tabular}

* $\mathrm{P}<0.05$

Tablo 7. Katılımcıların aylık gelirlerine göre fair-play davranışlarının değişimi

\begin{tabular}{|c|c|c|c|c|c|c|}
\hline & & $\mathrm{N}$ & Art.Ort. & $\begin{array}{l}\text { Std.Sap } \\
\text { ma }\end{array}$ & $\mathrm{F}$ & $\mathrm{P}$ \\
\hline \multirow{4}{*}{ Arkadaşa Saygı } & $0-1500$ & 84 & 7.11 & 2.88 & \multirow{4}{*}{1.748} & \multirow{4}{*}{.156} \\
\hline & $1500-3000$ & 215 & 6.94 & 2.73 & & \\
\hline & $3000-5000$ & 103 & 7.39 & 3.09 & & \\
\hline & 5000 Ve Üzeri & 48 & 7.93 & 3.24 & & \\
\hline \multirow{4}{*}{ Geleneklere Sayg1 } & $0-1500$ & 84 & 9.14 & 4.13 & \multirow{4}{*}{.534} & \multirow{4}{*}{.659} \\
\hline & $1500-3000$ & 215 & 8.65 & 4.53 & & \\
\hline & $3000-5000$ & 103 & 9.01 & 4.96 & & \\
\hline & $5000 \mathrm{Ve}$ Üzeri & 48 & 9.41 & 3.86 & & \\
\hline \multirow{4}{*}{ Haksız Kazanma } & $0-1500$ & 84 & 17.40 & 3.24 & \multirow{4}{*}{1.469} & \multirow{4}{*}{.222} \\
\hline & $1500-3000$ & 215 & 16.89 & 3.96 & & \\
\hline & $3000-5000$ & 103 & 16.21 & 4.54 & & \\
\hline & 5000 Ve Üzeri & 48 & 16.91 & 3.44 & & \\
\hline \multirow{4}{*}{ Hile } & $0-1500$ & 84 & 14.00 & 2.22 & \multirow{4}{*}{1.313} & \multirow{4}{*}{.269} \\
\hline & $1500-3000$ & 215 & 14.05 & 2.49 & & \\
\hline & $3000-5000$ & 103 & 13.43 & 3.38 & & \\
\hline & 5000 Ve Üzeri & 48 & 13.77 & 2.62 & & \\
\hline \multirow{4}{*}{ Fair Play } & $0-1500$ & 84 & 11.91 & 1.61 & \multirow{4}{*}{1.302} & \multirow{4}{*}{.273} \\
\hline & $1500-3000$ & 215 & 11.63 & 1.75 & & \\
\hline & $3000-5000$ & 103 & 11.51 & 2.09 & & \\
\hline & 5000 Ve Üzeri & 48 & 12.01 & 1.72 & & \\
\hline
\end{tabular}

Tablo 8'de demografik değişkenler ile fair-play Öğrenim durumu ile arkadaşa saygı arasında pozitif davranışları arasındaki ilişkisel analize yer verilmiştir. Yaş ile arkadaşa saygı alt boyutu arasında pozitif yönlü ilişki bulunmuştur $(\mathrm{r}=.113, \mathrm{p}<0.05)$. Cinsiyet ile haksız kazanma $(\mathrm{r}=-.096, \mathrm{p}<0.05)$ ve hile $(\mathrm{r}=-.169, \mathrm{p}<0.01)$ arasında negatif yönlü ilişkiler tespit edilmiştir. yönlü ilişki tespit edilmiştir $(\mathrm{r}=.112, \mathrm{p}<0.05)$. Baba ögrenim durumu ile arkadaşa saygı arasında pozitif yönlü $(\mathrm{r}=.163, \mathrm{p}<0.01)$, hile ile negatif yönlü ilişki tespit edilmiştir $(\mathrm{r}=-.114, \mathrm{p}<0.05)$. 
Tablo 8. Demografik değişkenler ile fair-play davranışları arasındaki ilişki

\begin{tabular}{|l|c|c|c|c|c|c|c|c|c|c|c|}
\hline Değişkenler & 1 & 2 & 3 & 4 & 5 & 6 & 7 & 8 & 9 & 10 & 11 \\
\hline 1. Yaş & 1 & & & & & & & & & & \\
\hline 2. Cinsiyet & .073 & 1 & & & & & & & & & \\
\hline 3. Öğrenim Durumu & $.678^{* *}$ & -.038 & 1 & & & & & & & & \\
\hline 4. Baba Öğrenim Durumu & $.097^{*}$ & -.031 & $.166^{* *}$ & 1 & & & & & & & \\
\hline 5. Anne Öğrenim Durumu & .056 & -.031 & $.133^{* *}$ & $.593^{* *}$ & 1 & & & & & & \\
\hline 6. Aile Aylik Gelir & .044 & $-.093^{*}$ & $.119^{*}$ & $.436^{* *}$ & $.411^{* *}$ & 1 & & & & & \\
\hline 7. Arkadaşa Sayg1 & $.113^{*}$ & .091 & $.112^{*}$ & $.163^{* *}$ & $.117^{*}$ & .086 & 1 & & & & \\
\hline 8. Geleneklere Sayg1 & .006 & .091 & -.004 & .040 & -.037 & .023 & $.326^{* *}$ & 1 & & & \\
\hline 9. Haks1z Kazanma & .062 & $-.096^{*}$ & -.010 & $-.096^{*}$ & -.090 & -.067 & $-.104^{*}$ & $-.273^{* *}$ & 1 & & \\
\hline 10. Hile & -.041 & $-.169^{* *}$ & -.069 & $-.114^{*}$ & $-.122^{* *}$ & -.061 & $-.191^{* * *}$ & $-.184^{* *}$ & $.573^{* *}$ & 1 & \\
\hline 11. Fair Play & .067 & -.022 & .011 & -.005 & -.070 & -.010 & $.475^{* *}$ & $.534^{* *}$ & $.545^{* *}$ & $.492^{* *}$ & 1 \\
\hline
\end{tabular}

Anne öğrenim durumu ile arkadaşa saygı arasında pozitif yönlü $(r=.117, p<0.05)$, hile ile negatif yönlü ilişki tespit edilmiştir $(\mathrm{r}=-.122, \mathrm{p}<0.01)$.

\section{Tartışma- Sonuc}

$\mathrm{Bu}$ araştırma, gençlik ve spor merkezlerinde çeşitli branşlarda düzenlenen kurslara katılan bireylerin fairplay davranışlarının çeşitli değişkenler açısından incelenmesi amacıyla gerçekleştirilmiştir. Araştırmada, arkadaşa saygı ve geleneklere saygı alt boyutlarında cinsiyetler arasında herhangi bir anlamlı farklılığa rastlanmazken, haksız kazanma ve hile alt boyutlarında ise cinsiyetler arasında anlamlı fark bulunmuştur.

Koç ve Güllü (2017) lise öğrencilerinde sportmenlik davranışlarını bazı değişkenlere göre inceledikleri çalışmada, sportmenlik davranışlarının cinsiyete ve spor türüne göre farklılaştığını bulmuşlardır. Gümüş ve diğerleri (2016) fair-play kavramı üzerine yaptıkları bir çalışmada, erkek öğrencilerin kadın öğrencilere göre sertliğe daha yatkın olduklarını, lisanslı öğrencilerin diğer öğrencilere göre oynadıkları takımın çıkarlarının söz konusu olduğunda fair-play kavramına daha az önem verdiğini tespit etmişlerdir. Esentürk ve arkadaşları (2015) bazı değişkenlere göre sportmenlik davranışlarını inceledikleri çalışmada, kız öğrencilerin puanlarında erkeklere oranla istatistiksel olarak anlamlı bir farklılık bulmuşlardır.

Araştırmada, fair-play davranışlarının araştırmaya katılan bireylerin branş dağılımlarına göre farklılaşmadığ1; katılımcıların öğrenim durumlarının, arkadaşa saygı alt boyutu dışında, fair-play davranışını değiştirmediği görülürken, arkadaşa saygı alt boyutunda yüksek lisans mezunlarının daha yüksek puana sahip olduğu tespit edilmiştir. Arkadaşa saygı boyutu dışındaki alt boyutlar ile toplam fair-play puanlarında anlamlı farklılık bulunamamıştır $(\mathrm{p}>0.05)$. Arkadaşa sayg1 alt boyutunda babası yüksek lisans mezunu olan bireylerin puanları ilkokul, ortaokul, lise mezunu olanlardan anlamlı düzeyde daha yüksektir $(\mathrm{p}<0.05)$. Arkadaşa saygı ve hile boyutlarında anlamlı farklılık tespit edilirken $(p<0.05)$, geleneklere sayg1 ve haksız kazanma boyutlarında herhangi bir anlamlı farklılık bulunamamıştır $(\mathrm{p}>0.05)$. Arkadaşa saygı alt boyutunda annesi yüksek lisans yapan bireylerin puanı, ilkokul ve ortaokuldan mezun olanlardan anlamlı düzeyde daha

yüksek bulunurken, hile alt boyutunda annesi yüksek lisans mezunu olan bireylerin puanları ilkokuldan, lise mezunu olanların puanları ise ilkokul mezunlarından daha düşük bulunmuştur. Katılımcıların aylık gelirlerine göre fair-play davranışlarının ise farklılaşmadığı tespit edilmiştir. Araştırmada, yaş ile arkadaşa saygı arasında pozitif yönlü ilişki bulunmuştur. Cinsiyet ile haksız kazanma ve hile arasında negatif yönlü ilişki tespit edilmiştir. Öğrenim durumu ile arkadaşa saygı arasında pozitif yönlü ilişki tespit edilmiştir. Baba öğrenim durumu ile arkadaşa saygı arasında pozitif yönlü, hile ile negatif yönlü ilişki tespit edilmiştir. Anne öğrenim durumu ile arkadaşa saygı arasında pozitif yönlü, hile ile negatif yönlü ilişki tespit edilmiştir.

Akandere ve arkadaşları (2009) sporcuların spora yönelmesi ile maddi gelir sağlama ve düzenli gelir elde etme değişkenleri arasında istatistiksel açıdan anlamlı bir ilişki olduğunu tespit etmiştir. Sporcu başarının ekonomik durumdan etkilendiği, spora başlamada yine gelir sağlama ve maddi kazanç elde etmenin önemli rol oynadığ 1 tespit edilirken, katılımcıların spora uzun süre devam etmeleri, profesyonel anlamda spora katılmaları ve eğitim, sağlık, barınma ve beslenme gibi başarılı olduklarında kazandıkları iyi hayat şartları, sporda başarısız oldukları zaman kaybetme endişesi maddi kazanç elde etme seçeneğinin yüksek olmasına neden olduğu belirtilmiştir.

Cengiz, Titrek ve Akgün (2007) bir ailenin sosyoekonomik düzeyinin, aile reisinin mesleğine, gelirine, taşınmaz mallarına, evin bulunduğu çevreyle aile üyelerinin yaşadığı sosyal çevreye, toplum içindeki sosyal statüleri ile anne ve babanın eğitim düzeyine göre belirlenmekte olduğunu vurgulamaktadırlar. Tel (2014), fair play üzerine yaptığı çalışmada, Türk toplum yaşantısında görülmekte olan birçok davranışın temelinde ahlaki değerlerin yattığını söylemenin mümkün olduğunu ve tüm yaşamda ahlaki değerlerin ön planda yer aldığını, bu değerlerin birçoğunun da günümüzde fair play olarak değerlendirilebileceğini belirtmektedir. 
Yıldırım (2017) tarafından sporcuların fair-play anlayışları üzerine yapılan bir çalışmada, okul ve kulüp takımlarında oynayan sporcuların, müsabaka öncesi, sırası ve sonrasında fair-play'e uygun davranışları büyük ölçüde gerçekleştirdiklerine, iç veya dış etkilerden kaynaklı bazı durumlarda ise fair-play anlayışına uymayan davranışlarda bulunduklarının belirlendiğine değinilmektedir. Zorba'da (2018), fair play davranışlarını incelemek amacıyla 187 öğrenci ile gerçekleştirdiği çalışmada, sporcularda bilinç oluşturma ve sporun etik değerleri ile ilgili gerekli yapısal değişiklikleri gerçekleştirebilmek için yapılan çalışmalar kapsamında, özellikle okul beden eğitimi dersleri ve okul dışı yarışmaların, sporcuların fair-play kavramına uygun davranışlar sergilemesi için bir ortam olarak kullanılması gerektiğine vurgu yapmaktadır. Sonuç olarak, araştırmadan elde edilen bulgulardan hareketle, katılımcıların öğrenim durumlarının, arkadaşa saygı boyutu dışında fair-play davranışını değiştirmediği, gençlik ve spor merkezlerinde açılan kurslara katılan bireylerin fair-play davranışlarının toplam değerlerinin cinsiyetlere göre değişmediği, bireylerin anne ve baba eğitim durumlarının fair-play davranışında kısmen farklılıklar oluşturduğu, aylık gelirin ise fair-play davranışlarında farklılık oluşturmadığı görülmüştür.

\section{Kaynaklar}

1. Akandere, M., Baştuğ, G. ve Akdoğan, Z. (2009). Erkek maratoncularda sosyal çevre ve ekonomik durumun spora yönelmeye etkisi. Selçuk Üniversitesi Sosyal Bilimler Enstitüsü Dergisi, (22), 459-466.

2. Baumann, S. (1994). Uygulamal Spor Psikolojisi. Alfa Basın Yayın Dağıtım, İstanbul.

3. Cengiz, G., Titrek, O. ve Akgün, Ö. E. (2007). Affect of school related factors in the student's choices of the high school. Journal of Human Sciences, 4(1), 1-22.

4. Erdemli, A. (1996). Insan, Spor ve Olimpizm (1 Bask1,). İstanbul. Sarmal Yayınevi, 151.

5. Esentürk, O.K, İlhan, E.L., \& Celik, O.B (2015). Examination Of High School Students' Sportsmanlike Conducts in Physical Education Lessons According to Some Variability. Science, Movement And Health, 15(2), 627-634.

6. Godin, G. (1994). L'esprit Sportif Ça Compte. 6e edition, Canada: Yvan Lépine.

7. Gümüş, H., Saraçlı, S., Karakullukçu, Ö.F., Doğanay, G., ve Kurtipek, S. (2016). International Journal of Science Culture and Sport, 4(Special Issue 2), 430-438.

8. Hu, L.T., \& Bentler, P.M. (1998). Fit indices in covariance structure modeling: Sensitivity to under parameterized model misspecification. Psychological methods, 3(4), 424 453.

9. Koç, Y. ve Güllü, M. (2017). Lise Öğrencilerinin Beden Eğitimi Dersi Sportmenlik Davranıslarının Bazı Değişkenlere Göre İncelenmesi. Spormetre, 15(1), 19-30.

10. Mirzeoğlu, N. (2015). The validity and reliability of Turkish version of fair play questionnaire in Physical Education (FPQ-PE) and an implementation. Educational Research and Reviews, 10(17), 2469-2480.

11. Nunnally, J., \& Bernstein, I. (1994). Psychometric theory. New York: McGraw-Hill.

12. Tel, M. (2014). Türk toplum yaşantısında fairplay. International Journal of Science Culture and Sport, 2 (Specia Issue 1), 694-704.
13. Tucker, L.W. \& Parks, J.B. (2001). Effects of gender and sport type on intercollegiate athletes perceptions of the legitimacy of aggressive behaviors in sport. Sociology of sport journal, 18 (4), 403-413.

14. Yıldıran, İ. (2004). Fair Play: Kapsamı, Türkiye'deki Görünümü ve Geliștirme Perspektifleri. Gazi Beden Eğitimi ve Spor Bilimleri Dergisi, 9(4), 3-16.

15. Yıldıran, İ. (2005). Fair Play Eğitiminde Beden Eğitiminin Rolü. Gazi Beden Eğitimi ve Spor Bilimleri Dergisi, 5(1), 3-16.

16. Yıldırım, M. (2017). Üniversitelerde Okul ve Kulüp Takımlarında Oynayan Sporcuların Sporda Fair-Play Anlayışlarının Belirlenmesi (Eskișehir Osmangaz Üniversitesi Örneği). İönü Üniversitesi Beden Eğitimi ve Spor Bilimleri Dergisi, 4(1), 1-15.

17. Zorba, E. (2018). Fair Play Behavior in Futsal: Study in High School Students. Universal Journal of Educational Research 6(7), 1449-1453.

http://edergi.cbu.edu.tr/ojs/index.php/cbusbed isimli yazarın CBU-SBED başlıklı eseri bu Creative Commons Alınt1-Gayriticari4.0 Uluslararası Lisansı ile lisanslanmıştır. 